\title{
Fibrous myopathy induced by intramuscular injections of cyclizine
}

DOI:

10.1136/bcr-2019-233544

\section{Document Version}

Accepted author manuscript

Link to publication record in Manchester Research Explorer

\section{Citation for published version (APA):}

Tinker, R. J., Wiltshire, R., Du Plessis, D., \& Lilleker, J. B. (2020). Fibrous myopathy induced by intramuscular injections of cyclizine. BMJ Case Reports, 13(5), [e233544]. https://doi.org/10.1136/bcr-2019-233544

\section{Published in:}

BMJ Case Reports

\section{Citing this paper}

Please note that where the full-text provided on Manchester Research Explorer is the Author Accepted Manuscript or Proof version this may differ from the final Published version. If citing, it is advised that you check and use the publisher's definitive version.

\section{General rights}

Copyright and moral rights for the publications made accessible in the Research Explorer are retained by the authors and/or other copyright owners and it is a condition of accessing publications that users recognise and abide by the legal requirements associated with these rights.

\section{Takedown policy}

If you believe that this document breaches copyright please refer to the University of Manchester's Takedown Procedures [http://man.ac.uk/04Y6Bo] or contact uml.scholarlycommunications@manchester.ac.uk providing relevant details, so we can investigate your claim.

\section{OPEN ACCESS}


Rory J Tinkera, Ryan Wiltshirea, Daniel du Plessis ${ }^{b}$, James B Lilleker ${ }^{b, c}$

a Faculty of Biology, Medicine and Health, University of Manchester, Manchester, M13 9PL, UK.

b Manchester Centre for Clinical Neuroscience, Salford Royal NHS Foundation Trust, Manchester

Academic Health Science Centre, Manchester, UK.

c Centre for Musculoskeletal Research, School of Biological Sciences, Faculty of Biology Medicine and Health, Manchester Academic Health Science Centre, University of Manchester, Manchester, UK james.lilleker@manchester.ac.uk.

\section{SUMMARY}

A 63-year-old woman was referred to neurology with bilateral severe progressive pain and stiffness in her thighs. The patient had a three-year history of injecting intramuscular (IM) cyclizine into the anterior thigh to treat nausea associated with a longstanding pan-enteric dysmotility syndrome. An MRI scan of the thighs demonstrated fibrotic appearances. A biopsy of the left vastus lateralis and surrounding fascia identified pathology consistent with a fibrous myopathy. The patient was advised to stop IM injections of cyclizine and underwent physiotherapy but remained in considerable pain. Whilst fibrous myopathy occurring as a consequence of recurrent IM drug injections, particularly heroin, has been previously described, this is the first report of fibrous myopathy associated with the use of IM cyclizine. We highlight this rare association and suggest that long-term use of IM cyclizine is avoided.

\section{BACKGROUND}

Cyclizine is a H1-receptor antagonist (antihistamine) used to treat and prevent nausea, vomiting and dizziness ${ }^{[1]}$. It can be administered orally, as a suppository, or by intravenous or intramuscular (IM) injection [1]. Common side effects include drowsiness, xerostomia, constipation hypotension and urinary retention [2]. A benefit of IM injection is that due to the large vascular supply of skeletal muscle, especially in comparison to subcutaneous tissue, there is a higher rate of absorption ${ }^{[3-4]}$. Complications of IM injections are rare, but can include hematoma formation, aseptic tissue necrosis, nerve injury, cellulitis and infective myositis [4]. In addition, certain medicinal agents can trigger secondary pathology, including a fibrous myopathy ${ }^{[5] .}$

Fibrous myopathy is a subtype of the toxic myopathies ${ }^{[6-7]}$. These disorders involve an acute or subacute myopathic syndrome, generally occurring in patients without pre-existing muscle disease, after exposure to certain drugs ${ }^{[6]}$. The most common medication induced toxic myopathy is statin related myotoxicity. In fibrous myopathy, normal tissue is replaced by a fibrous connective tissue and can be triggered by recurrent IM injections of medicinal agents or illicit drugs, particularly heroin [8-9]. The condition usually presents with a painless, fibrous, hard and indurated muscle which is stiff in both active and passive movement ${ }^{[8-9]}$. Serum creatine kinase and electromyography are normal [8-9]. Ultrasound imaging usually demonstrates an enlargement of muscle structure with thickened connective tissue ${ }^{[8-9]}$. On biopsy, muscle fibers may show 
abnormal variation in size and replacement by endomysial connective tissue ${ }^{[8-9]}$. Fibrous myopathy has been previously treated with suspension of the causative IM injection, administration of prednisone or penicillamine, and physical therapy ${ }^{[8-9]}$. Here we highlight the first reported case of fibrous myopathy associated with longterm use of IM cyclizine.

\section{CASE PRESENTATION}

A 63-year-old woman was referred to an outpatient neurology clinic at a tertiary neurosciences centre in the Northwest of England. For the previous three years, the patient had been injecting IM cyclizine to treat nausea associated with pan-enteric dysmotility syndrome. Initially the patient injected into the deltoids but switched to the anterior thigh after these sites became painful. The patient injected IM cyclizine three times a day for three years. This resulted in approximately 3,285 injections. The patient subsequently developed bilateral progressive generalised hip and thigh pain, evolving over a twelve-month period. The pain was eased by non-steroidal antiinflammatory medication and was associated with bilateral weakness, stiffness and cramping in her thighs, shoulder and calves.

The patient had initially presented to orthopaedics after a right displaced intracapsular neck of femur fracture sustained during a fall down the stairs. Orthopaedics colleagues noted that the pain and associated symptoms were unrelated to the hip displacement, especially as they had been present and progressing before the fracture occurred.

The patient had an extensive medical history including coeliac disease, generalised intestinal dysmotility syndrome, anxiety, depression, stress incontinence and L5/S1 degenerative disc disease with no neuronal compression. Surgically, the patient had previously undergone a subtotal colectomy and small bowel resection to treat slow transit constipation, an appendectomy, a cholecystectomy to treat gall stones and a bladder prolapse repair.

On examination, the patient's thighs appeared bruised and both knees had a 70-degree fixed flexion deformity. There was significant stiffness of the quadriceps muscles bilaterally. On neurological examination the patient had an antalgic gait and was mobilising with two crutches due to the significant pain and stiffness over the thigh muscle. There was limited power in hip flexion. Otherwise, the rest of the neurological examination (cranial nerves, upper and lower limbs) was normal. 
The differential list considered for the patient are presented in Table 1.

\begin{tabular}{|l|l|}
\hline Differential & $\begin{array}{l}\text { Factors reducing diagnostic probability in this } \\
\text { case }\end{array}$ \\
\hline Avascular necrosis of hip fracture & MRI demonstrated no hip fracture pathology \\
\hline Polymyalgia rheumatic & Normal inflammatory markers \\
\hline Inflammatory myopathy & Normal inflammatory markers and creatine kinase \\
\hline Mixed connective tissue disease & Negative antibody screen \\
\hline
\end{tabular}

Table 1. The major differentials for subacute progressive thigh pain and weakness. Adapted from [10-13]

Routine blood tests including serum total creatine kinase and inflammatory markers were normal. A myositis anti-extractable nuclear antigen autoantibody screen was negative. An MRI scan of the hips and thighs was reviewed which demonstrated extensive bilateral fibrous myopathic changes in the anterolateral thighs (Figure 1).

This raised the diagnostic probability of a toxic myopathy and thus a left vastus lateralis muscle biopsy was performed to investigate further. This showed extensive displacement and entrapment of muscle by marked peri- and endomysial sclerosis accompanied by limited, focal perivascular lymphocytic cuffing by $\mathrm{T}$ lymphocytes with no evidence of vasculopathy including vasculitis or macrophage activity (Figure 2). The histology was consistent with a fibrous myopathy due to recurrent injection of a medicinal agent into the thigh muscles.

\section{TREATMENT}

The patient was managed with a multidisciplinary approach. The IM cyclizine injections were suspended and substituted for oral ondansetron. However, this failed to adequately control her nausea and she was subsequently offered subcutaneous levomepromazine. Pain management specialists increased the oral morphine dose and counselled her on pain self-management. Furthermore, the patient was referred to physiotherapy for global lower limb exercises with a view to increasing exercise tolerance and strength. Occupational therapy assessed the patient's home for adaptation considering her potential long-term reduction in musculoskeletal strength. 


\section{OUTCOME AND FOLLOW-UP}

Unfortunately, the patient declined subcutaneous levomepromazine to control her nausea because of concerns relating to the possible increased thrombotic risk associated with this medication. At her discretion, the patient elected to continue to inject IM cyclizine, but was encouraged to vary injection sites as much as possible.

\section{DISCUSSION}

This case demonstrates extensive replacement of normal muscle tissue with fibrous connective tissue in a patient using long-term IM cyclizine injected into the same area. The development of fibrous myopathy substantially reduced the functional abilities of the patient. This resulted in further disability in addition to the suffering already associated with her chronic nausea.

Fibrous myopathy has previously been reported in both painful and painless forms [14-21]. Several medications have been reported as potential causes of fibrous myopathy when used IM, including pentazocine, butorphanol, propoxyphene, heroin, piritramide, methadone and meperidine [14-21]. It is unclear if fibrous myopathy is the result of repeated needle related muscle trauma or the myotoxic properties of the injected agents. The difference in pharmacokinetic properties between cyclizine and the narcotic analgesics adds further complexity to ascertaining the pathological mechanism. Cyclizine IM injection contains lactic acid and

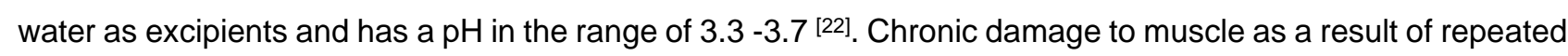
mechanical injury, as well as the acidic $\mathrm{pH}$ of the injected material, are both likely to contribute to the dysfunctional and uncoordinated muscular repair and fibrous replacement of muscle tissue seen in our patient [23].

There are uncertainties as to whether the risk of developing fibrous myopathy derives from the total number of injections, the dose of each injection, or the frequency of injections. Investigation of how these factors contribute to the pathology in fibrous myopathy could be a focus of future research. In the case reported here, the patient injected IM cyclizine three times a day for three years, resulting in approximately 3,285 injections. Whilst fibrous myopathy has also been shown to occur in patients with fewer injections, the range varies widely between 100's to 10,000's [14-21].

There is a paucity of robust evidence in the literature to support any particular therapeutic strategy or prognostic factors. There are also uncertainties regarding the potential reversibility of fibrous myopathy. In the case reported here the symptoms did not resolve or improve after the cessation of IM injections for six months and the muscle imaging demonstrated significant muscle damage. However, it has previously been reported that fibrous myopathy (after 500 injections of IM heroin) was reversible after suspension of IM injections and administration of glucocorticoids and penicillamine ${ }^{[16]}$. It is possible that the relatively lower number of IM injections in this previous report contributed to the reversibility observed. Whilst it could be postulated that increasing levels of muscle fibrosis are associated with a lower capacity for recovery and a poorer outcome, the exact relationship between the severity of the pathology and prognosis is poorly understood. The establishment of an international cohort of patients with fibrous myopathy could provide an opportunity to 
understand the factors associated with prognosis in standardised fashion

In light of this case we suggest that IM cyclizine should be avoided if long-term treatment is required, particularly if variable injection sites are not able to be utilised. If there is no reasonable alternative, then clinicians and patients should have a low threshold for considering the development of fibrous myopathy so that the injections can be stopped before permanent damage to muscle occurs. 
- Fibrous myopathy is a reported consequence of the IM injection of analgesics and now cyclizine.

- Fibrous myopathy can lead to significant morbidity.

- A multidisciplinary team approach is needed to investigate and treat patients presenting with symptoms of fibrous myopathy.

- Further research is required to identify the mechanism of how IM injections of certain medications results in fibrous myopathy.

\section{REFERENCES}

1) Schmäl, F. (2013). "Neuronal Mechanisms and the Treatment of Motion Sickness." Pharmacology 91(3-4): 229-241..

2) Laffey, J. G. and J. F. Boylan (2002). "Cyclizine and droperidol have comparable efficacy and side effects during patient-controlled analgesia." Ir J Med Sci 171(3): 141-144.

3) Nakajima, Y., et al. (2017). "Establishing a new appropriate IM injection site in the deltoid muscle." Human vaccines \& immunotherapeutics 13(9): 2123-2129.

4) Puschmann, T. and B. Ohnesorge (2015). "Complications After IM Injections in Equids." Journal of Equine Veterinary Science 35(6): 465-474.

5) Burnham, R., et al. (2006). "Fibrous myopathy as a complication of repeated IM injections for chronic headache." Pain research \& management 11(4): 249-252.

6) Dalakas, M. C. (2009). "Toxic and drug-induced myopathies." J Neurol Neurosurg Psychiatry 80(8): 832-838.

7) Weber, M., et al. (2000). "Focal myopathy induced by chronic heroin injection is reversible." Muscle Nerve 23(2): 274-277.

8) https://www.orpha.net/consor/cgi-bin/OC_Exp.php?Expert=48918

9) Kim LYS. Compression neuropathy of the radial nerve due to pentazocine-induced fibrous myopathy. Arch Phys Med Rehabil. 1987;68:49-50.

10) Guerado, E. and E. Caso (2016). "The physiopathology of avascular necrosis of the femoral head: an update." Injury 47 Suppl 6: S16-s26.

11) Acharya, S. and R. Musa (2019). Polymyalgia Rheumatica. StatPearls. Treasure Island (FL), StatPearls Publishing.

12) Tieu, J., et al. (2016). "Idiopathic inflammatory myositis." Best Pract Res Clin Rheumatol 30(1): 149- 168.

13) Chaigne, B., et al. (2018). "Mixed connective tissue disease: state of the art on clinical practice guidelines." RMD Open 4(Suppl 1): e000783.

14) Wagner JM, Cohen S. Fibrous myopathy from butorphanol injections. J Rheumatol. 1991;18:1934-5.

15) Restrepo JF, Guzman R, Pena MA, et al. Fibrous myopathy induced by propoxyphene injections. J Rheumatol. 1993;20:596-7.

16) Weber M, Diener HC, Voit T, Neuen-Jacob E. Focal myopathy induced by chronic heroin injection is reversible. Muscle Nerve. 2000;23:274-7.

17) Van den Bergh PYK, Guettat L, Vande Berg BC, Martin J. Focal myopathy associated with chronic IM injection of piritramide. Muscle Nerve. 1997;20:1598-600.

18) Carpintero P, Kindelan J, Lluch M, Mesa M. Methadone-induced fibrous and calcified myopathy - A report of 2 cases. Acta Orthop Scand. 1996;67:404-6.

19) Johnson KR, Hsueh WA, Glusman SM, Arnett FC. Fibrous myopathy. A rheumatic complication of drug abuse. Arthritis Rheum. 1976;19:923-6.

20) Brumback RA, Empting L, Susag ME, Staton RD. Muscle fibrosis associated with IM chlorpromazine administration. A preliminary report. J Pharm Pharmacol. 1982;34:526-8. 
21) Norman MG, Temple AR, Murphy JV. Infantile quadriceps femoris contracture resulting from IM injections. N Engl J Med. 1970;282:964-6.

22) Medicines.org.uk. (2020). Cyclizine Lactate $50 \mathrm{mg} / \mathrm{ml}$ Solution for Injection - Summary of Product Characteristics (SmPC) - (emc). [online] Available at: https://www.medicines.org.uk/emc/product/9275/smpc [Accessed 19 Feb. 2020].

23) Mann, C. J., et al. (2011). "Aberrant repair and fibrosis development in skeletal muscle." Skelet Muscle 1(1): 21.

Figure 1. Magnetic resonance imaging (T1 (1A, 1B and 1C) and Short-TI Inversion Recovery (1D, 1E and $1 \mathrm{~F})$ ) demonstrating extensive fibrous myopathic changes bilateral in the anterolateral thighs.

Figure 2. Biopsy of the left vastus lateralis muscle demonstrates marked fibrosis of endomysium and perimysium, severe loss of myofibers and moderately severe-tosevere atrophy of residual myofibers. Haematoxylin and eosin stain, original magnification $\times 50$. 
INTELLECTUAL PROPERTY RIGHTS ASSIGNMENT OR LICENCE STATEMENT

I Rory James Tinker, the Author has the right to grant and does grant on behalf of all authors, an exclusive licence and/or a non-exclusive licence for contributions from authors who are: i) UK Crown employees; ii) where BMJ has agreed a CC-BY licence shall apply, and/or iii) in accordance with the relevant stated licence terms for US Federal Government Employees acting in the course of the their employment, on a worldwide basis to the BMJ Publishing Group Ltd ("BMJ") and its licensees, to permit this Work (as defined in the below licence), if accepted, to be published in BMJ Case Reports and any other BMJ products and to exploit all rights, as set out in our licence author licence.

Date: $11 / 11 / 19$ 